\section{Imaging of the small bowel by capsule endoscopy in Whipple's disease}

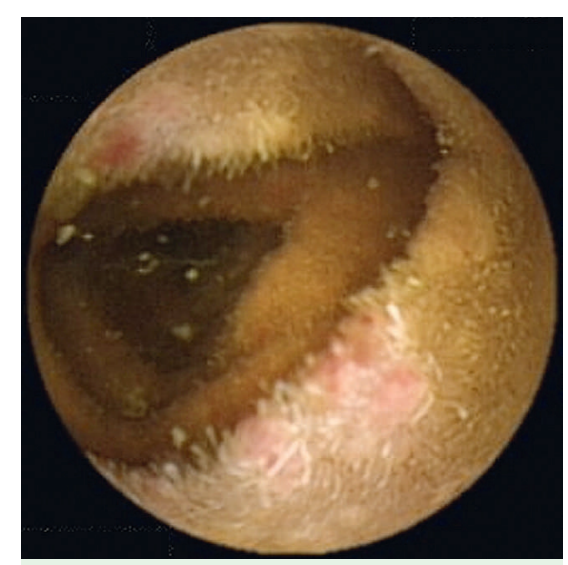

Fig. 1 Capsule endoscopy in Whipple's disease.

A 40-year-old male plasterer was assessed in the gastroenterology outpatient clinic to investigate the cause of iron-deficiency anemia and raised inflammatory markers (hemoglobin $7.7 \mathrm{~g} / \mathrm{dL}$, mean corpuscular volume $67 \mathrm{fl}$, iron level $2 \mu \mathrm{mol} / \mathrm{L}$, erythrocyte sedimentation rate $106 \mathrm{~mm} /$ hour, Creactive protein $91 \mathrm{mg} / \mathrm{L}$ ). On direct questioning he reported a 2-year history of lethargy, 6-kg weight loss despite a normal appetite, and no bowel symptoms. On examination the patient was visibly cachectic, and had gynecomastia and axillary lymphadenopathy. He was admitted to hospital for further investigations.

A thoracoabdominal computed tomography scan showed abdominal lymphadenopathy, which was thought to be reactive. A gastroscopy showed significant candida esophagitis and ulcerative duodenitis. A capsule endoscopy revealed that the ulcerations extended throughout the proximal small bowel and were accompanied by nodules and hemorrhagic spots ( Fig. 1; $\odot$ Video 1 ).

\section{Video 1}

Capsule endoscopy in Whipple's disease. Colonoscopy and terminal ileoscopy were normal. Biopsies taken from the second part of the duodenum showed abundant foamy pink macrophages that contained intense, periodic acid Schiff (PAS)-positive, diastase-resistant cytoplasmic inclusions. These findings were consistent with Whipple's disease.
Whipple's disease is rare, and endoscopic changes tend to be within the small bowel, which has meant there are very few reports of the endoscopic appearance of the disease. A recent case series has reported edema of the duodenum, brown discoloration of the mucosa, erythematous spots, and subepithelial hemorrhages [1]. A previous report of capsule endoscopy in a case of Whipple's disease that was unresponsive to antibiotics noted areas of bleeding throughout the jejunum [2]. We observed similar changes in the duodenum, which extended throughout the proximal small bowel, prior to the start of antibiotic treatment. Interestingly, although gross features were only observed in the duodenum and jejunum, identical histologic features were found in the duodenum, ileum, and colonic biopsies. With more evidence for the endoscopic appearances of Whipple's disease becoming available, capsule endoscopy promises to be a useful diagnostic tool in this disease.

Endoscopy_UCTN_Code_CCL_1AC_2AD

M. G. Keane ${ }^{1}$, M. Shariff ${ }^{1}$, J. Stocks ${ }^{2}$, P. Trembling ${ }^{1}$, P. P. Cohen ${ }^{1}$, G. Smith ${ }^{1}$

${ }^{1}$ Gastroenterology Department, Charing

Cross Hospital, London, UK

2 Gastroenterology Department, Hammersmith Hospital, London, UK

\section{References}

1 Monkemuller K, Fry LC, Von Arnim U et al. Whipple's disease: an endoscopic and histologic study. Digestion 2008; 77: $161-165$

2 Fritscher-Ravens $A$, Swain $C P$, von Herbay $A$. Refractory Whipple's disease with anaemia: first lessons from capsule endoscopy. Endoscopy 2004; 36: 659-662
Bibliography

DOI 10.1055/s-0028-1119729

Endoscopy 2009; 41: E139

(c) Georg Thieme Verlag KG Stuttgart · New York . ISSN 0013-726X

\section{Corresponding author}

\section{G. Keane, MBBS BSC}

Gastroenterology Department

Charing Cross Hospital

Fulham Palace Rd

London

W6 8RF

UK

Fax: +44-207-4034338

geri.keane@doctors.net.uk 